\title{
An Absolute Calibration of the National Bureau of Standards Thermal Neutron Flux
}

\author{
E. J. Axton ${ }^{1}$ \\ (February 12, 1963)
}

\begin{abstract}
The NBS Thermal Neutron Flux has been calibrated in terms of the gold thermal neutron capture cross section. The effective thermal neutron (below cadmium cutoff energy) flux density is estimated to be $4307 \pm 2$ percent $n / \mathrm{cm}^{2}$ sec in September 1961 . This figure is in agreement with a recent value quoted by the NBS.
\end{abstract}

\section{Introduction}

The NBS Standard Thermal Neutron Flux has been calibrated in terms of the $B(n, \alpha)$ cross section [De Juren and Rosenwasser, 1954] and of the gold thermal neutron capture cross section [Mosburg and Murphey, 1961]. The present calibration, based on absolute counting of ${ }^{198} \mathrm{Au}$ activity by the $4 \pi \beta-\gamma$ coincidence method, represents part of a program of international comparisons of thermal neutron flux density measurement.

\section{Method and Procedure}

The method is similar to that used for the absolute calibration of the neutron flux in the AERE reactor GLEEP [Axton, 1963]. This calibration was based on absolute counting of ${ }^{56} \mathrm{Mn}$ and of ${ }^{198} \mathrm{Au}$ by the $4 \pi \beta-\gamma$ coincidence method, and some of the same gold foils and the same counting equipment are used in the present experiment, so that the various correction factors associated with the foils and equipment have already been evaluated and, where appropriate, are reproduced in table 1.

\section{TABLE 1}

\begin{tabular}{|c|c|c|c|c|c|c|c|c|}
\hline \multirow{2}{*}{ Foil } & \multirow{2}{*}{$\begin{array}{c}\text { Mass } \\
\text { mg }\end{array}$} & \multirow{2}{*}{$\begin{array}{l}\text { Nominal } \\
\text { thickness } \\
\mathrm{mg} / \mathrm{cm}^{2}\end{array}$} & \multicolumn{6}{|c|}{ Foil data } \\
\hline & & & $N_{\beta} / N$ & $1 / F$ & $F_{\mathrm{C} d \mathrm{~d}}$ & $f_{(\delta)}$ & $G_{t}$ & $g \sigma_{0}$ \\
\hline $\begin{array}{l}G_{1} \\
G^{2} \\
G_{3} \\
G_{4}\end{array}$ & $\begin{array}{l}23.19 \\
23.48 \\
23.44 \\
22.97\end{array}$ & $\begin{array}{l}30 \\
30 \\
30 \\
30\end{array}$ & $\begin{array}{r}0.6841 \\
.6924 \\
.6896 \\
.6961\end{array}$ & 1. 028 & 1. 01 & 0.991 & 0.441 & 99.32 \\
\hline
\end{tabular}

A pair of foils $\left(G_{1}, G_{2}\right) 30 \mathrm{mg} / \mathrm{cm}^{2}$ in thickness and $1 \mathrm{~cm}$ diam were irradiated in the flux for one week. A similar pair $\left(G_{3}, G_{4}\right)$, encased in cadmium $0.1 \mathrm{~cm}$ thick, were irradiated for 11 days.

The foils were counted in the $4 \pi \beta$ counter of the coincidence equipment previously described [Axton, 1963]. For $G_{1}, G_{2}$, the total counting rate was approximately $11 \mathrm{c} / \mathrm{s}$ against a background of 0.9 $\mathrm{c} / \mathrm{s}$. For $G_{3}, G_{4}$, the counting rate was approximately $2.2 \mathrm{c} / \mathrm{s}$, against a background counting rate of $0.9 \mathrm{c} / \mathrm{s}$. In view of the low counting rate it was not possible to make coincidence measurements on these foils.

1 National Physical Laboratory, Dept. of Scientific and Iudustrial Research, Teddington, Middlesex, Enoland. (An invited paper.)
However, the ratio between $N_{\beta}$, the net counting rate in the $4 \pi \beta$ counter, and $N$, the absolute disintegration rate has been measured for these foils a number of times both before and after this irradiation in the course of the GLEEP flux measurement.

The reaction rate $D_{0}$ per milligram of foil is obtained from the equation

$$
D_{0}=\frac{D \exp \left[\lambda\left(t_{3}-t_{2}\right)\right] \lambda\left(t_{4}-t_{3}\right)}{\left\{1-\exp \left[-\lambda\left(t_{2}-t_{1}\right)\right]\right\}\left\{1-\exp \left[-\lambda\left(t_{4}-t_{3}\right)\right]\right\}}
$$

where $\lambda$ is the decay constant of ${ }^{198} \mathrm{Au}$ and $D$ is the average disintegration rate per $\mathrm{mg}$ from time $t_{3}$ to time $t_{4}$ of a foil irradiated from time $t_{1}$ to time $t_{2}$.

The thermal neutron flux density, defined as $n_{\text {th }}$ $v_{0}$, where $n_{\text {th }}$ is the neutron density below the cadmium cutoff energy, and $v_{0}=2200 \mathrm{~m} / \mathrm{sec}$, is given by

$$
n_{\mathrm{th}} v_{0}=\frac{(1 / F)\left(D_{0}-D_{0 \mathrm{Cd}} F_{\mathrm{Cd}}\right) A}{0.001 N_{0} g \sigma_{0}}
$$

where

$D_{0 \text { Cd }} \quad$ is the reaction rate per mg obtained with the foil under cadmium.

$F_{\text {Cd }}$ is a correction factor for the attenuation of resonance neutrons in the cadmium.

$1 / F \quad$ is a correction factor for thermal neutron flux density depression and self shielding.

$g \sigma_{0} \quad$ is the effective absorption cross section for neutrons with a Maxwellian distribution of velocities at $20^{\circ} \mathrm{C}$.

$\sigma_{0} \quad=98.8 \mathrm{~b}$ (Hughes and Schwartz, 1958).

$g \quad=1.0053$ (Westcott, 1960).

$A=$ Atomic Weight.

$N_{0}=$ Avogradro's Number.

The values of both $F$ and $g$ are dependent upon the temperature $T$ associated with the most probable velocity in the Maxwellian distribution. The temperature is assumed here to be $T_{0}$ to conform to the value of $g$ quoted by Mosburg and Murphey [1961]. $T_{0}=293.6^{\circ} \mathrm{K}$ and $k T_{0}$ is the energy corresponding to the neutron velocity $v_{\mathrm{c}}=2200 \mathrm{~m} / \mathrm{sec}$ at which thermal cross sections are normally tabulated. 
$1 / F=X /\left[1 / 2-E_{3}(X)\right]$ where $X=\sum_{\text {eff }} t=\frac{N_{0} t}{\mathrm{~A}}$

$$
\times 1.08 g \sigma_{0}\left(T_{0} / T\right)^{1 / 2}
$$

and

$$
E_{3}(X)=\int_{1}^{\infty} u^{-3} \exp (-u X) d u
$$

$t$ is the foil thickness in $\mathrm{g} / \mathrm{cm}^{2}$.

\section{Results}

The results are presented in table 2 from which it can be deduced that the effective thermal neutron (below cadmium cutoff energy) flux density is given by

$$
n_{\text {th }} \imath_{0}=4307 \mathrm{n} / \mathrm{cm}^{2} \mathrm{sec} .
$$

\begin{tabular}{|c|c|c|c|c|c|c|}
\hline Foil & $\begin{array}{l}N_{\beta} \mathrm{c} / \mathrm{s} \\
\text { corrected for } \\
\text { decay }\end{array}$ & $\begin{array}{c}D_{0} \\
\mathrm{dps} / \mathrm{mg}\end{array}$ & $\begin{array}{l}D_{0} \mathrm{Cd} \\
\mathrm{dps} / \mathrm{mg}\end{array}$ & $R_{\mathrm{Cd}}$ & $r$ & $\begin{array}{l}\quad n_{\text {th }} v_{0} \\
\text { Septem- } \\
\text { ber } 1961\end{array}$ \\
\hline $\begin{array}{c}G_{1} \\
G^{2} \\
G_{3} \\
G_{4} \\
\text { Mean }\end{array}$ & $\begin{array}{c}19.961 \\
20.209 \\
3.4257 \\
3.2981 \\
\end{array}$ & $\begin{array}{r}1.507 \\
1.489 \\
1.498\end{array}$ & $\begin{array}{r}.2260 \\
.2200 \\
.2230\end{array}$ & $\begin{array}{l}-\cdots \\
-\cdots \\
-\cdots .72\end{array}$ & 0.0212 & 4307 \\
\hline
\end{tabular}

TABLE 2. Results

For comparison purposes the values of $n_{\mathrm{th}} v_{0}$ obtained at NBS are presented in table 3, column 1, and corrected to September 1961 in column 2 .

However, the procedure used to calculate the neutron flux differs from that of Mosburg and Murphey [1961] in three respects.

Firstly, the value 1.048 calculated by Mosburg and Murphey, and used by them for the correction factor $F_{\mathrm{Cd}}$ is believed to be too large. The calculation of this factor is difficult, since it involves an effective cross section for cadmium. To obtain such an effective cross section it is not sufficient to calculate the absorption of the resonance neutrons in the cadmium; nor is it sufficient to measure the reduction of the activity produced by a further equal thickness of cadmium. This follows because the activity of the cadmium covered foil is not produced wholly by the resonance-energy neutrons. Mosburg and Murphey used the cadmium total cross section at the gold resonance energy in their calculation of $F_{\mathrm{Cd}}$. However, to satisfy the experimentally derived value for $F_{\mathrm{Cd}}$ quoted in table 1, it is necessary to use only the capture cross section plus a fraction of the scatter cross section. This fraction is expected to vary with foil thickness as will the relative contribution of the resonanceenergy neutrons to the activity of the cadmium covered foil. However, there are insufficient data available at the present time to establish variations of $F_{\mathrm{Cd}}$ with foil thickness. Thus, the experimentally determined value for these particular foils and cadmium covers (table 1 ) is preferred. If the results of Mosburg and Murphey, who used similar thicknesses, are recalculated using this value of $F_{\mathrm{Cd}}$,

\begin{tabular}{|c|c|c|c|}
\hline & \multicolumn{3}{|c|}{$n_{\mathrm{th}} v_{0}$} \\
\hline & $\begin{array}{l}\text { Published } \\
\text { value } \\
n / \mathrm{cm}^{2} \mathrm{sec}\end{array}$ & $\begin{array}{c}\begin{array}{c}\text { Corrected } \\
\text { for polonium } \\
\text { growth } \\
\text { September } 1961 \\
\\
n / \mathrm{cm}^{2} \mathrm{sec}\end{array}\end{array}$ & $\begin{array}{c}\text { Corrected for } \\
\text { change in } F_{\mathrm{Cd}} \\
\text { and in effective } \\
\text { cross sections } \\
\text { September } 1961 \\
n / \mathrm{cm}^{2} \mathrm{sec}\end{array}$ \\
\hline $\begin{array}{l}\text { NBS (Gold) Mosburg- } \\
\text { Murphey, [1961] } \\
\text { NBS (Boron) De Juren } \\
\text { and Rosen wasser, } \\
\text { [1954]. } \\
\text { Weighted mean a } \\
\text { Ratio NPL measure- } \\
\text { ment/NBS weighted } \\
\text { mean. }\end{array}$ & $\begin{array}{l}4167 \pm 1.5 \% \\
4276 \pm 2 \% \\
4203 \pm 1.5 \%\end{array}$ & $\begin{array}{l}4188 \pm 1.5 \% \\
4297 \pm 2 \% \\
4224 \pm 1.5 \%\end{array}$ & $\begin{array}{l}4195 \\
4297 \\
4229 \pm 1.5 \%\end{array}$ \\
\hline
\end{tabular}
the flux value is raised by about 0.6 percent.
TABLE 3. Comparison of NBS and NPL measurements

a The means given here are those quoted by Mosburg and Murphey (1961), who give arbitrary weights of 2 and 1 to the gold and boron measurements, respectively.

Secondly, the effective cross section $g \sigma_{0}$ is used instead of $\sigma_{0}$ to derive the neutron flux from the foil activity. This results in a reduction of about 0.5 percent and almost cancels out the first change.

Thirdly, the effective cross section $1.08 g \sigma_{0}$ is used instead of $\sigma_{0}$ to derive the foil self-absorption correction.

The results of Mosburg and Murphey [1961] have been recalculated with these changes to produce the revised value for the neutron flux density shown in column 3.

Thus the ratio $\frac{\text { NPL flux density measurement }}{\text { NBS flux density measurement }} 1.020$, which reduces to 1.018 if the adjustments to $F_{\mathrm{Cd}}$ and to the cross sections are made in the calculation of the NBS gold value.

It is sometimes of interest to specify the neutron flux density in terms of the total neutron density $n$, or of the density in some specific component of the flux. In order to do this with detectors whose cross section does not follow the $1 / v$ law, it is necessary to assume a spectrum shape, which, in the case of wellmoderated reactors, usually comprises a Maxwellian distribution of velocities at temperature $T^{\circ} \mathrm{K}$ and a $d E / E$ component terminated at an effective lower limit $\mu k T$. With the present system of point sources, it is unlikely that the spectrum follows the $1 / E$ law very closely. Nevertheless, in the absence of specific information, the $d E / E$ assumption has been made for the purposes of the following calculations, and the results therefore should be treated with reserve.

The relative intensity of the $d E / E$ component is derived from cadmium ratio measurements. The cadmium ratio $R_{\mathrm{Cd}}$ (ratio of activity obtained with bare foil to that obtained with cadmium covered foil) is given by the equation

$$
R_{\mathrm{Cd}}=\frac{F\left(r \sqrt{T / T_{0}}\right)^{-1}+G_{t} s_{0} / g}{1 / K+f(\delta) G_{t}\left(s_{0} / g-W\right)}
$$


which is based on the equation of Walker et al. [1960] with (a) the addition of the self-shielding factor $F$, and (b) the assumption of zero penetration of thermal neutrons through the cadmium.

$s_{0} \quad$ is a function of the resonance integral $s_{0}=17.3 \quad$ [Westcott 1960] $\left(s_{0}\right.$ is the $T=T_{0}$ value of Westcott's $s_{4}$ ).

$W \quad$ is a function of the resonance integral below the cadmium cutoff energy. $W=0.027$. [Walker et al. 1960].

$K$ is a function of the cadmium cutoff energy. For $0.1 \mathrm{~cm} \mathrm{Cd}, K=2.2931$ [Westcott et al. 1958].

$r \quad$ is a measure of the relative intensity of the $d E / E$ component. The fraction of the neutron density in the $d E / E$ component of flux is $4 r(\pi \mu)^{-\frac{1}{2}}$.

$g \quad 1.0053$

accounts for the self-screening of the resonance-energy neutrons in the foil.

$f(\delta) \quad$ accounts for the attenuation of the resonance-energy neutrons in the cadmium cover.

$G_{t}$ and $f(\delta)$ are reproduced in table 1 from a previous paper [Axton, 1963].

For a full discussion on the meanings of these terms the reader is referred to the literature.

Thus, with the experimentally determined value for $R_{\mathrm{Cd}}$ the value of $r$ can be calculated from eq (3). The value so obtained is $r=0.0212$. The total flux density $n v_{0}$ is then given by

$$
\begin{aligned}
n v_{0}=n_{\mathrm{th}} v_{0}(R / R-1)= & n_{\mathrm{th}} v_{0}(1-r / K)^{-1} \\
& =n_{\mathrm{th}} v_{0} / 0.9908=4347 \mathrm{~m} / \mathrm{cm}^{2} \mathrm{sec}
\end{aligned}
$$

where $R$ is the cadmium ratio which would be obtained with a thin $1 / v$ detector. $R=K / r$ from eq (3) with $F=1, T=T_{0}, s_{0}=W=0$. It appears that changes as high as 20 percent in the value of $r$ have very little effect on the value obtained for the total neutron flux density.

The Maxwellian flux density $n_{m} v_{0}$ (where $n_{m}$ is the neutron density in the Maxwellian component of the flux) is given by

$$
n_{m} v_{0}=n v_{0}\left(1-\frac{4 r}{(\pi \mu)^{\frac{1}{2}}}\right)=0.9751 n v_{0}=4239 \mathrm{~m} / \mathrm{cm}^{2} \mathrm{sec} .
$$

The value of $\mu$, which is determined by the effective lower energy limit of the $d E / E$ component of the flux, is a matter for some discussion. The value used here (3.681) is that for which $s_{0}$ was computed.

\section{Accuracy of Results}

Table 4 shows the various errors $\alpha$ associated with the calculation of the thermal neutron flux density, together with the weights $\omega$ with which they influence the result.

The sum $\left[\Sigma(\omega \alpha)^{2}\right]^{1 / 2}$ is less than \pm 1 percent. In addition, there may be a systematic error not exceeding \pm 1 percent associated with the absolute measurement of the radioactivity. The combined error is thus \pm 2 percent.

It is concluded that NBS and NPL measurements of thermal neutron flux density are in agreement within the limits of experimental error.

The author is grateful for the cooperation of the National Bureau of Standards in this work, which has been carried out as part of the general research program of the National Physical Laboratory, and this paper is published with the permission of the

\begin{tabular}{|c|c|c|}
\hline Error & Weight $\omega$ & Error $\alpha$ \\
\hline $\begin{array}{l}\text { Counting statistics: } \\
\text { (Bare foil and background) } \\
\text { (Foil in Cd and background) } \\
N_{\beta} / N \text { (Bare foil) } \\
N_{\beta} / N \text { (Foil in Cd) } \\
\text { Mass (Bare foil) } \\
\text { Mass (Foil in Cd) } \\
F \\
F_{\mathrm{Cd}}\end{array}$ & $\begin{array}{r}0.832 \\
.124 \\
.832 \\
.124 \\
.832 \\
.124 \\
1.175 \\
1^{.175}\end{array}$ & $\begin{aligned} & \% \\
& 0.4 \\
& 1.4 \\
& .75 \\
& .75 \\
& .1 \\
& .1 \\
& .3 \\
& .5 \\
& .4\end{aligned}$ \\
\hline
\end{tabular}
Director.

TABLE 4. Errors associated with flux density measurement

\section{References}

Axton, E. J., J. Nucl. Energy, Part A Reactor Science 17, No. 5 (May 1963)

De Juren, J. and Rosenwasser, H., J. Research, NBS $\mathbf{5 2 ,} 93$ (1954).

Hughes, D. J. and Schwartz, R. B., BNL 325 2d Ed (1958).

Mosburg, E. R. and Murphey, W. M., J. Nucl. Energy 14, 25 (1961).

Westcott, C. H., CRRP, 960 (1960).

Westcott, C. H., Walker, W. H., and Alexander, T. K., A./Conf. $15 / \mathrm{P} / 202$.

Walker, W. H., Westcott, C. H., and Alexander, T. K., Can. J. Phys. 38, 57 (1960). 